\title{
Dexmedetomidine sedation reduces atrial fibrillation after cardiac surgery compared to propofol: a randomized controlled trial
}

\author{
Xu Liu, Kai Zhang, Wei Wang, Guohao Xie and Xiangming Fang*
}

\begin{abstract}
Background: Atrial fibrillation occurs frequently in patients following cardiac surgery and can be a cause of increased morbidity and mortality. The use of dexmedetomidine to prevent atrial fibrillation is unclear. The present study was designed to evaluate the effect of dexmedetomidine sedation on the incidence of atrial fibrillation after cardiac surgery.

Methods: Upon arrival to the intensive care unit (ICU), cardiac surgery patients without prior atrial fibrillation or flutter were randomized to receive either dexmedetomidine $(0.2-1.5 \mu \mathrm{g} / \mathrm{kg} / \mathrm{h})$ or propofol $(0.3-3 \mathrm{mg} / \mathrm{kg} / \mathrm{h})$ open-label titrated to a target Richmond agitation-sedation scale of 0 to -3 . Our primary endpoint was the incidence of postoperative atrial fibrillation, and the secondary end points were the length of ICU stay, length of hospital stay, and hospital costs.
\end{abstract}

Results: Atrial fibrillation occurred in 6 of 44 patients (13.6\%) in the dexmedetomidine group compared to 16 of 44 patients (36.4\%) in the propofol group (odds ratio $=0.28 ; 95 \%$ confidence interval, $0.10,0.80 ; P=0.025$ ). The median (interquartile range) length of ICU stay in the dexmedetomidine group was significantly lower than in the propofol group (2.9 (2.4-3.5) vs 3.5 (2.7-4.5 days, $P=0.008)$, with a trend toward a decrease in median hospital costs ( 86,367 vs 77,874 Chinese yuan; $P=0.068$ ). The incidence of hypotension was higher in the dexmedetomidine group than in the propofol group (25/44 (56.8 \%) vs 13/44 (29.5\%); $P=0.017)$.

Conclusions: Dexmedetomidine sedation reduced the incidence of new-onset postoperative atrial fibrillation and shortened the length of ICU stay in patients after cardiac surgery compared to propofol sedation.

Dexmedetomidine treatment was associated with more episodes of hypotension.

Trial registration: chictr.org.cn: ChiCTR-IPR-16008231, retrospectively registered: April 6, 2016.

This trial was not prospectively registered due to a lack of importance applied to trial registration.

Keywords: Atrial fibrillation, Cardiac surgery, Dexmedetomidine, Propofol, Sedation

\section{Background}

Atrial fibrillation (AF) is the most common complication and the most common arrhythmia detected following cardiac surgery [1-4]. The incidence of AF in patients after cardiac surgery has been reported to range between 15 and $50 \%$ [5-7], with patients undergoing valve surgery being at the greatest risk [8]. In addition, AF most commonly occurs within 4 days postoperatively

\footnotetext{
*Correspondence: xiangming_fang@163.com

Department of Anesthesiology and Intensive Care Medicine, the First Affiliated Hospital, School of Medicine, Zhejiang University, 79 Qingchun Road, 310003 Hangzhou, China
}

$[5,8]$. Postoperative AF is associated with a prolonged hospital stay, higher costs, and increased morbidity and mortality [4-8].

Although a number of prophylactic strategies for the prevention of postoperative AF have been proposed, they are not routinely implemented in many clinical centers $[9,10]$, including ours. The major reasons for non-use include a lack of convincing evidence, potential risks associated with current drug therapies, and complexity of some prevention regimens $[11,12]$. Sedatives and analgesics are routinely administered to most patients undergoing cardiac surgery to reduce anxiety and pain 
$[13,14]$. Dexmedetomidine has been used as a safe and efficacious sedative agent in patients undergoing cardiac surgery $[15,16]$, without pro-tachyarrhythmic or negative inotropic effects [17]. Moreover, dexmedetomidine is associated with decreased incidence of postoperative supraventricular and ventricular tachyarrhythmia and has been found to terminate supraventricular tachycardia in pediatric patients [18-20]. Recently, two retrospective studies also showed that dexmedetomidine sedation might decrease atrial arrhythmia in adult patients after cardiovascular surgery $[21,22]$. It appears that dexmedetomidine sedation would be a good choice for the prevention of postoperative AF. However, previous studies have been subject to selection bias and many confounders due to the observational design. Furthermore, the aforementioned studies did not directly compare dexmedetomidine with propofol, which is used in current standard practice for sedation after cardiac surgery.

We designed and implemented a prospective randomized controlled trial (RCT) to determine whether dexmedetomidine reduces the incidence of postoperative AF while effectively sedating mechanically ventilated patients after cardiac surgery, when compared to propofol sedation.

\section{Methods}

\section{Patient population}

This prospective randomized controlled clinical trial was approved by the Ethics Committee of the First Affiliated Hospital of Zhejiang University and registered at chictr.org.cn (ChiCTR-IPR-16008231). This study was conducted in the First Affiliated Hospital of Zhejiang University between January 2015 and December 2015. Written informed consent was obtained from the patient or next of kin before enrollment. The inclusion criteria were as follows: age $\geq 18$ years, elective cardiac surgery with cardiopulmonary bypass (CPB), admitted to intensive care unit (ICU) while intubated and ventilated, and lack of prior AF or flutter before receiving sedation in the ICU. Patients were excluded when they had at least one of the following characteristics at arrival in the ICU: heart rate $<50$ beats per minute, atrioventricular conduction block of grade II or III (unless a pacemaker had been installed), mean arterial pressure (MAP) $<55 \mathrm{mmHg}$ (despite appropriate intravenous volume replacement and vasopressor treatment), acute severe neurological disorder, propofol or dexmedetomidine allergy or other contraindications. In addition, patients who had received two or more sedatives within $24 \mathrm{~h}$ postoperatively were also excluded.

\section{Randomization, masking and intervention}

Patients received standard anesthesia including induction with midazolam and sufentanil and paralysis with cisatracurium and maintenance with sevoflurane, propofol and sufentanil. During CPB, the administration of sevoflurane was stopped. The bypass circuit was primed with $1000 \mathrm{~mL}$ of lactated Ringer solution, $100 \mathrm{~mL}$ of $5 \%$ sodium bicarbonate and $200 \mathrm{~mL}$ of $20 \%$ mannitol. Prior to aortic cannulation, heparin was adjusted to maintain an activated clotting time longer than 450 seconds. The pump flow rates ranged from 1.8 to $2.4 \mathrm{~L} / \mathrm{min} / \mathrm{m}^{2}$. The core temperature was controlled at 32 to $34{ }^{\circ} \mathrm{C}$ using a heat exchanger in the bypass circuit. After surgery, the patients were transferred to the ICU. Upon arrival at the ICU, the patient's blood pressure, electrocardiograms and oxygen saturation were monitored. The patients were randomized in a 1:1 ratio to receive sedation with either propofol (control) or dexmedetomidine according to the random number table.

Dexmedetomidine or propofol was continuously infused without a loading dose. Sedation levels were evaluated with the Richmond agitation-sedation scale (RASS), which ranges from -5 (unarousable) to 4 (combative). An assessment of RASS was performed every $2 \mathrm{~h}$ or more often if required (e.g., if the patient's condition changed). The intravenous infusion speed of dexmedetomidine $(\leq 1.5 \mu \mathrm{g} / \mathrm{kg} / \mathrm{h})$ or propofol $(\leq 3 \mu \mathrm{mg} / \mathrm{kg} / \mathrm{h})$ was adjusted to maintain RASS values between 0 and -3 $[23,24]$. When hypotension (MAP $<65 \mathrm{mmHg}$ ) and/or bradycardia (heart rate $<60$ beats/minute) lasted longer than 5 minutes, the infusion of the sedative was stopped until the patient exhibited blood pressure and heart rate within an acceptable range. The infusion of the sedative was stopped before extubation at the discretion of the attending physicians.

Sufentanil was continuously infused (usually at a rate of $0.06 \mu \mathrm{g} / \mathrm{kg} / \mathrm{h}$ ) for intravenous analgesia and discontinued until a total dose of $200 \mu \mathrm{g}$ had been administered. Pain was assessed using the visual analog scale (VAS) (range 0 (no pain) to 10 (maximal pain)). If the VAS score was $>3$ [25], additional analgesia (morphine or tramadol) was provided.

\section{Outcome measures}

The primary outcome was the incidence of AF within $96 \mathrm{~h}$ of surgery. Postoperative AF was defined as no consistent P waves before each QRS complex and an irregular ventricular rate [3]. Each patient underwent continuous electrocardiographic monitoring for at least $96 \mathrm{~h}$ after surgery. The investigators recorded the time of AF onset when they detected AF on the electrocardiogram displayed on the bedside monitor, and a twelvelead electrocardiographic recording was performed to confirm the rhythm if necessary. AF episodes lasting longer than 5 minutes were recorded [3].

Adverse events recorded during the ICU stay included: bradycardia (heart rate $<60$ beats/minute for $>5$ minutes [26]), hypotension (MAP $<65 \mathrm{mmHg}$ for $>3$ minutes), 
and postoperative nausea/vomiting and delirium (identified with a confusion assessment method for the ICU). Acute kidney injury was diagnosed according to Acute Kidney Injury Network (AKIN) criteria: an absolute increase in serum creatinine $\geq 26.4 \mu \mathrm{mol} / \mathrm{L}$, percentage increase in serum creatinine $\geq 50 \%$ (1.5-fold from baseline), or urine output $<0.5 \mathrm{ml} / \mathrm{kg} / \mathrm{h}$ for $>6 \mathrm{~h}$ within $48 \mathrm{~h}$ after surgery [27]. The intubation time (time from ICU admission to the time of extubation), length of ICU stay, length of (postoperative) hospital stay and hospital fees were also recorded.

\section{Statistical analysis}

Sample size determination was based on an expected $35 \%$ occurrence of postoperative AF in the propofol group and an expected $10 \%$ occurrence of AF in the dexmedetomidine group [11, 22, 28]. At a significance level of 0.05 with a power of 0.80 , the resulting sample size was 40 patients in each group. Anticipating a dropout rate of approximately $10 \%$, a sample size of 45 patients in each group was considered to be appropriate. Data were described using descriptive statistics and presented as the median (interquartile range) unless indicated otherwise. All continuous variables were analyzed using the Mann-Whitney $U$ test due to the relatively small numbers. Categorical variables were compared using the Fisher exact test. Kaplan-Meier curves were generated for postoperative AF. SPSS (SPSS 16.0 for Windows; SPSS, Chicago, IL, USA) and GraphPad Prism 5.04 (GraphPad Software, La Jolla, CA, USA) were used for statistical analyses. A $P$ value $<0.05$ (two-sided) was regarded as statistically significant.

\section{Results}

A total of 479 patients were assessed for eligibility after cardiac surgery with CPB (Fig. 1). After 389 patients were excluded, 90 patients were randomly assigned to two groups: 45 patients received propofol and 45 patients received dexmedetomidine. One patient in each group was also infused with the other sedative within $24 \mathrm{~h}$ after surgery. Therefore, 44 patients in each group were included in the analysis. There were no differences between the groups in baseline demographic and surgical characteristics (Table 1).

There were 22 patients who had AF during the first $96 \mathrm{~h}$ after cardiac surgery with $\mathrm{CPB}$. Patients assigned to receive dexmedetomidine were significantly less likely to have AF than patients assigned to receive propofol (6 (13.6\%) vs 16 (36.4\%); odds ratio, 0.28 ; $95 \%$ confidence interval, $0.10,0.80 ; P=0.025$; number needed to treat, 4.4) (Table 2). The relative risk reduction was $62.6 \%$. The Kaplan-Meier incidence of postoperative AF in the dexmedetomidine group and propofol group is shown in Fig. 2. In patients who had received dexmedetomidine, the median onset of AF tended to be delayed compared with control patients (Table 2).

One patient in the propofol group died on the second postoperative day due to cardiac failure. There were no statistically significant differences between the groups in peak postoperative cardiac troponin I (cTnI), bradycardia, nausea and vomiting, mechanical ventilation $\geq 24 \mathrm{~h}$, acute kidney injury, or delirium (Table 2). However, the incidence of hypotension was significantly higher in the dexmedetomidine group than in the propofol group (Table 2). Patients with hypotension recovered quickly

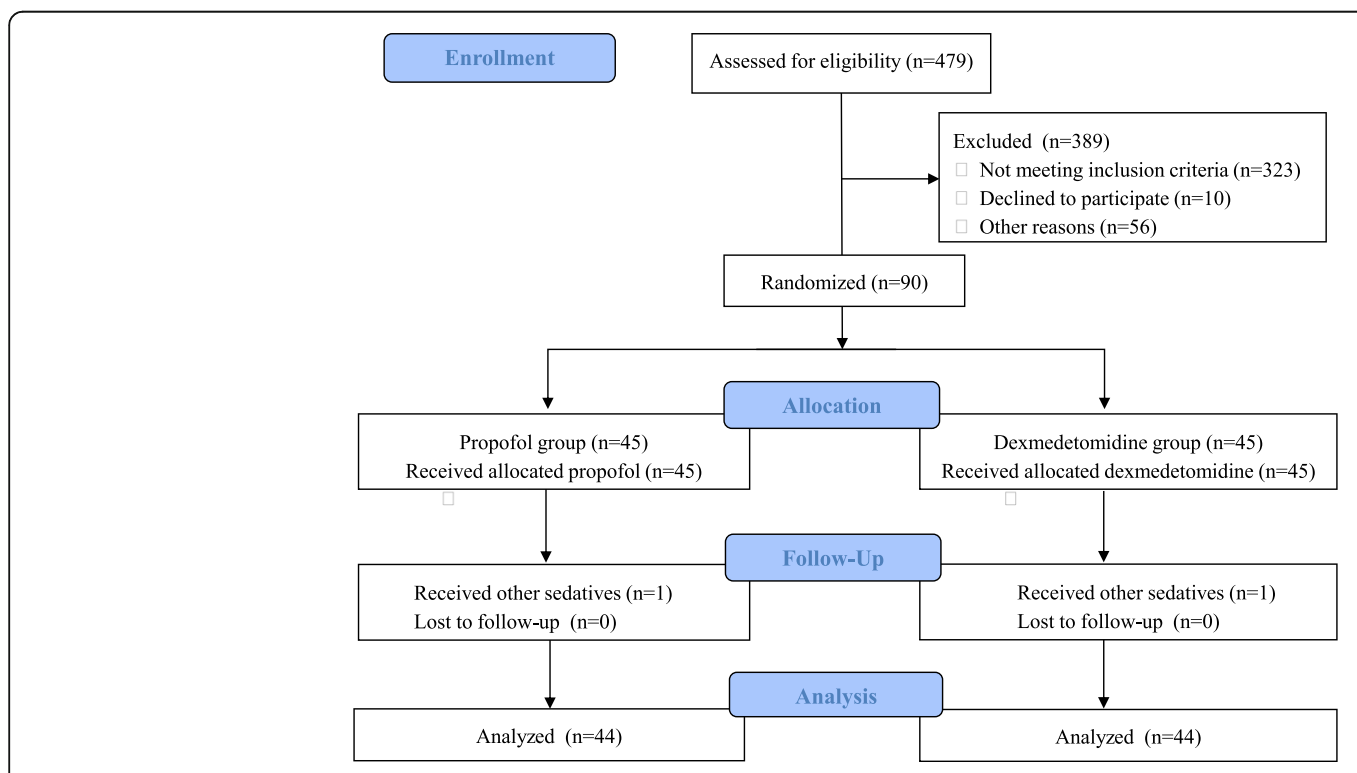

Fig. 1 Consort flow diagram of the study participants 
Table 1 Baseline demographic and surgical characteristics of the study population

\begin{tabular}{|c|c|c|c|}
\hline Characteristics & $\begin{array}{l}\text { Propofol } \\
(n=44)\end{array}$ & $\begin{array}{l}\text { Dexmedetomidine } \\
(n=44)\end{array}$ & $P$ value \\
\hline Age, years & $56.5(49.3-62.0)$ & $53.0(46.0-63.0)$ & 0.314 \\
\hline Female gender & $30(68.2)$ & $23(52.3)$ & 0.191 \\
\hline Body mass index, $\mathrm{kg} / \mathrm{m}^{2}$ & $21.8(20.0-25.1)$ & $22.4(20.8-24.6)$ & 0.607 \\
\hline Hypertension & $13(29.5)$ & $13(29.5)$ & $>0.999$ \\
\hline Diabetes & $5(11.4)$ & $6(13.6)$ & $>0.999$ \\
\hline Smoking history & $10(22.7)$ & $18(40.9)$ & 0.108 \\
\hline $\begin{array}{l}\text { Chronic obstructive } \\
\text { pulmonary disease }\end{array}$ & $2(4.5)$ & $4(9.1)$ & 0.676 \\
\hline $\begin{array}{l}\text { Left ventricular ejection } \\
\text { fraction, } \%\end{array}$ & $65.0(57.0-71.0)$ & $65.0(56.8-71.0)$ & 0.975 \\
\hline $\begin{array}{l}\text { New York Heart } \\
\text { Association class }\end{array}$ & & & 0.561 \\
\hline । & $2(4.5)$ & $2(4.5)$ & \\
\hline$\|$ & $28(63.6)$ & $29(65.9)$ & \\
\hline III & $12(27.3)$ & $13(29.5)$ & \\
\hline IV & $2(4.5)$ & $0(0)$ & \\
\hline $\begin{array}{l}\text { Preoperative use of } \\
\beta \text {-blockers }\end{array}$ & $5(11.4)$ & $1(2.3)$ & 0.202 \\
\hline $\begin{array}{l}\text { Preoperative use of } \\
\text { digoxin }\end{array}$ & $20(45.5)$ & $20(45.5)$ & $>0.999$ \\
\hline Type of operation & & & 0.616 \\
\hline Mitral valve surgery & $8(18.2)$ & $11(25.0)$ & \\
\hline Aortic valve surgery & $15(34.1)$ & $15(34.1)$ & \\
\hline $\begin{array}{l}\text { Mitral + aortic valve } \\
\text { surgery }\end{array}$ & $13(29.5)$ & $8(18.2)$ & \\
\hline$C A B G+$ valve surgery & $1(2.3)$ & $3(6.8)$ & \\
\hline Other cardiac surgery & $7(15.9)$ & $7(15.9)$ & \\
\hline $\begin{array}{l}\text { Cardiopulmonary bypass } \\
\text { time, minutes }\end{array}$ & $68.8(53.8-93.6)$ & $73.5(55.7-85.1)$ & 0.635 \\
\hline Cross-clamp time, minutes & $47.3(36.6-67.1)$ & $50.7(34.2-62.4)$ & 0.892 \\
\hline $\begin{array}{l}\text { Defibrillation after } \\
\text { reperfusion }\end{array}$ & $14(31.8)$ & $18(40.9)$ & 0.507 \\
\hline $\begin{array}{l}\text { Temporary pacemaker } \\
\text { insertion }{ }^{\mathrm{a}}\end{array}$ & $7(15.9)$ & $6(13.6)$ & $>0.999$ \\
\hline
\end{tabular}

Data are presented as the median (interquartile range) or number (\%).

aventricular pacing. CABG coronary artery bypass graft

after intravenous fluid replacement and/or adjusting the infusion speed of vasoactive drugs. The details of sedation and analgesia are reflected in Table 3.

Medical resource utilization is also reported in Table 2. Although the intubation time, length of hospital stay and postoperative hospital days were similar in the two groups, the length of ICU stay was significantly shorter in the dexmedetomidine group than in the propofol group (2.9 (2.4-3.5) vs 3.5 (2.7-4.5 days, $P=0.008)$, with a trend toward a decrease in median hospital fees (86,367 vs 77,874 Chinese yuan, $P=0.068$ ). Patients who experienced postoperative AF were significantly older
Table 2 Postoperative characteristics and resource utilization of the patient groups

\begin{tabular}{|c|c|c|c|}
\hline Characteristics & $\begin{array}{l}\text { Propofol } \\
(n=44)\end{array}$ & $\begin{array}{l}\text { Dexmedetomidine } \\
(n=44)\end{array}$ & $\begin{array}{l}P \\
\text { value }\end{array}$ \\
\hline $\begin{array}{l}\text { AF during } 96 \mathrm{~h} \text { after } \\
\text { surgery }\end{array}$ & $16(36.4)$ & $6(13.6)$ & 0.025 \\
\hline $\begin{array}{l}\text { Onset of AF } \\
\text { (h after operation) }\end{array}$ & $25.5(19.5-36.4)$ & $40.4(19.3-53.1)$ & 0.261 \\
\hline In-hospital mortality & $1(2.3)$ & $0(0)$ & $>0.999$ \\
\hline $\begin{array}{l}\text { Mortality during study } \\
\text { period }\end{array}$ & $1(2.3)$ & $0(0)$ & $>0.999$ \\
\hline $\begin{array}{l}\text { Serum potassium before } \\
A F, m m o l / L\end{array}$ & $4.2(3.9-4.3)$ & $4.0(3 .-4.1)$ & 0.083 \\
\hline $\begin{array}{l}\text { Peak postoperative cTnl, } \\
\mathrm{ng} / \mathrm{mL}\end{array}$ & $5.5(2.9-9.5)$ & $6.9(2.6-11.8)$ & 0.611 \\
\hline Hypotension & $13(29.5)$ & $25(56.8)$ & 0.017 \\
\hline Bradycardia & $1(2.3)$ & $4(9.1)$ & 0.360 \\
\hline Nausea/vomiting & $10(22.7)$ & $9(20.5)$ & $>0.999$ \\
\hline Delirium & $5(11.4)$ & $0(0)$ & 0.055 \\
\hline Acute kidney injury & $3(6.8)$ & $5(11.4)$ & 0.713 \\
\hline $\begin{array}{l}\text { Mechanical ventilation } \\
\geq 24 \mathrm{~h}\end{array}$ & $6(13.6)$ & $4(9.1)$ & 0.739 \\
\hline Intubation time, $\mathrm{h}$ & $21.2(17.0-22.8)$ & $21.0(16.9-22.5)$ & 0.757 \\
\hline Length of ICU stay, days & $3.5(2.7-4.5)$ & $2.9(2.4-3.5)$ & 0.008 \\
\hline $\begin{array}{l}\text { Length of hospital stay, } \\
\text { days }\end{array}$ & $14.0(11.0-17.0)$ & $13.5(11.3-17.0)$ & 0.983 \\
\hline Postoperative hospital days & $8.0(7.0-10.0)$ & $8.0(7.0-9.8)$ & 0.505 \\
\hline $\begin{array}{l}\text { Hospital fees, Chinese } \\
\text { yuan, } \times 10^{4}\end{array}$ & $8.64(7.32-9.63)$ & $7.79(6.72-9.05)$ & 0.068 \\
\hline
\end{tabular}

Data are presented as the number (\%) or median (interquartile range). $A F$ atrial fibrillation, $C T n /$ cardiac troponin I, ICU intensive care unit

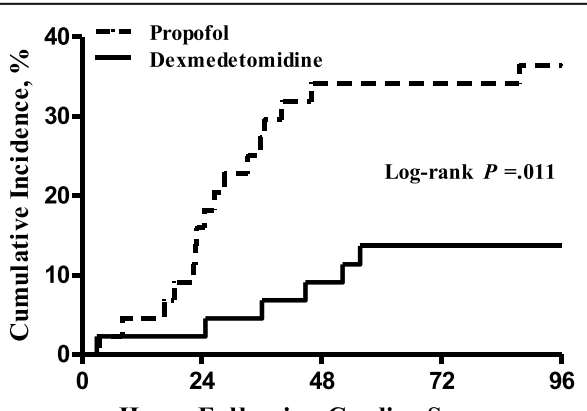

No. at risk

Hours Following Cardiac Surgery

$\begin{array}{llllll}\text { Propofol } & 44 & 37 & 29 & 29 & 28 \\ \text { Dexmedetomidine } & 44 & 43 & 40 & 38 & 38\end{array}$

Fig. $\mathbf{2}$ Kaplan-Meier incidence of postoperative atrial fibrillation according to treatment group 
Table 3 Details of sedation and analgesia in propofol and dexmedetomidine groups

\begin{tabular}{llll}
\hline & Propofol $(n=44)$ & $\begin{array}{l}\text { Dexmedetomidine } \\
(n=44)\end{array}$ & $P$ value \\
\hline RASS at $4 \mathrm{~h}$ & $-2(-3$ to -1$)$ & $-2(-2$ to -1$)$ & 0.488 \\
VAS at $24 \mathrm{~h}$ & $1.0(1-2)$ & $1.5(1-2)$ & 0.935 \\
$\begin{array}{l}\text { Extra analgesic } \\
\text { requirements }\end{array}$ & $4(9.1)$ & $5(11.4)$ & $>0.999$ \\
$\begin{array}{l}\text { Infusion speed at } 4 \mathrm{~h}, \\
\mathrm{mg} / \mathrm{kg} / \mathrm{h} \text { or } \mu \mathrm{g} / \mathrm{kg} / \mathrm{h}\end{array}$ & $0.98(0.77$ to 1.23$)$ & $0.68(0.48$ to 0.82) & \\
$\begin{array}{l}\text { Total dosage, } \mathrm{mg} \text { or } \mu \mathrm{g} \\
\text { Infusion time, minutes }\end{array}$ & $900(625$ to 1100$)$ & $572(448$ to 720$)$ & \\
\hline
\end{tabular}

Data are presented as the median (interquartile range) or $n(\%) .{ }^{a}$ Number of patients who received extra analgesic treatment within $24 \mathrm{~h}$ after surgery. RASS Richmond agitation-sedation scale, VAS visual analog scale

and had a longer ICU stay, more postoperative hospital days and higher hospital fees compared to patients without postoperative AF (Table 4).

\section{Discussion}

To our knowledge, the current study is the first prospective randomized trial confirming that dexmedetomidine sedation reduces new-onset postoperative AF and shortens the length of ICU stay with a trend toward a decrease in hospital costs, compared to propofol sedation. The absolute risk reduction for AF was $22.8 \%$ in patients following cardiac surgery, with a number needed to treat of 4.4, suggesting that dexmedetomidine administration during the early postoperative period could prevent one case of AF for every five patients. In addition, our results also demonstrated that postoperative AF was associated with a longer stay in the ICU, more postoperative hospital days and increased hospital fees.

Dexmedetomidine is an $\alpha_{2}$ adrenergic receptor agonist that induces sedative, anxiolytic and analgesic effects without causing respiratory depression $[18,29]$ and has been increasingly used for sedation in cardiac surgery patients $[16,29]$. A small retrospective study $(n=45)$ reported that patients undergoing cardiovascular surgery who received dexmedetomidine were less likely to have new-onset AF than patients who did not receive any sedative drugs [22], which supports the results of the current study. However, a recent meta-analysis showed that dexmedetomidine was not associated with a decrease in the incidence of postoperative AF in patients undergoing cardiac surgery [30]. The potential reasons for this inconsistency may be the fact that postoperative AF was not the primary outcome, an explicit and consistent definition of AF was lacking, different observation periods were used for detecting $\mathrm{AF}$, a large variety of types of surgery and drug regimens were included in those studies [31-36], and patients with prior AF were not excluded in most studies [31-35]. Some patients had a history of chronic, recurrent AF that was resistant to chemical cardioversion [18]. Consequently, the inclusion of patients with prior AF in the study may have concealed the efficacy of dexmedetomidine to reduce postoperative AF.

Several potential factors could contribute to the effect of dexmedetomidine on preventing new-onset postoperative AF. First, dexmedetomidine could reduce myocardial ischemia-reperfusion injury and improve the perfusion of the myocardium in patients undergoing cardiac surgery $[16,36]$. Second, the inflammatory response induced by cardiac surgery and bypass can alter atrial electrophysiology and structural substrates, leading to increased vulnerability to AF [14, 37]. Dexmedetomidine has been shown to inhibit the inflammatory response in animal models [38, 39] and in clinical trials [40, 41]. Tasdogan et al. [41] found that postoperative patients who received dexmedetomidine had significantly lower levels of tumor necrosis factor-alpha, interleukin-1 and interleukin- 6 than those who received propofol. Third, increased adrenergic tone plays a role in the development of postoperative AF

Table 4 Comparison of patients with and without atrial fibrillation (AF) or flutter

\begin{tabular}{llll}
\hline Characteristics & Patients with AF $(n=22)$ & Patients without AF $(n=66)$ & $P$ value \\
\hline Age, years & $62.5(57.8-68.3)$ & $52.0(45.5-61.0)$ & $<7(56.1)$ \\
Female gender, $n(\%)$ & $16(72.7)$ & $22.2(19.8-24.0)$ & 0.212 \\
Body mass index, $\mathrm{kg} / \mathrm{m}^{2}$ & $23.4(20.9-27.1)$ & $68.8(55.2-85.1)$ & 0.124 \\
Cardiopulmonary bypass time, minutes & $74.7(61.0-96.0)$ & $48.2(33.8-64.6)$ & 0.527 \\
Cross-Clamp time, minutes & $48.5(40.6-64.1)$ & $21.0(17.3-22.5)$ & 0.643 \\
Intubation time, $\mathrm{h}$ & $21.2(16.6-22.8)$ & $2.9(2.4-3.7)$ & 0.528 \\
Length of ICU stay, days & $3.8(2.9-4.8)$ & $13.0(11.0-16.0)$ & 0.002 \\
Length of hospital stay, days & $15.0(13.0-17.5)$ & $8.0(7.0-9.0)$ & 0.117 \\
Postoperative hospital days & $9.5(8.0-11.0)$ & $7.80(6.69-9.13)$ & 0.021 \\
Hospital fees, Chinese yuan, $\times 10^{4}$ & $8.91(8.10-10.22)$ & & 0.006 \\
\hline
\end{tabular}

Data are presented as the median (interquartile range) unless otherwise stated. ICU intensive care unit 
[42]. Dexmedetomidine can decrease catecholamines [43] and inhibit the arrhythmogenic effect of epinephrine [44]. Fourth, dexmedetomidine can enhance vagal activity, leading to alterations in $\mathrm{Ca}^{2+}$ currents across the myocyte cell membrane, which in turn could result in prolonged repolarization and an increased effective refractory period [17]. Based on the combination of organ-protective, antiinflammatory, sympatholytic and parasympathomimetic effects, it is not surprising that the use of dexmedetomidine during the early postoperative period could be beneficial in preventing AF after cardiac surgery.

An increased risk of bradycardia and hypotension can be a concern of dexmedetomidine [23, 24]. In this study, hypotension was more common among dexmedetomidinetreated patients despite the similar levels of sedation attained by patients treated with dexmedetomidine and propofol. However, hypotension was quickly rectified after intravenous fluid replacement and/or adjusting the infusion speed of the vasoactive or sedative drug, which rarely necessitated stopping the study in either group.

This study has several limitations. Fist, there was no blinding of the propofol and dexmedetomidine infusions in our study. However, the diagnosis of AF was made by continuous electrocardiogram (ECG) monitoring and/or 12-lead ECG, and the practitioners who identified AF were not aware of the study objectives.

Second, routine prophylactic strategies for postoperative $\mathrm{AF}$, such as the perioperative use of $\beta$-blockers, were not implemented in our study. The choice of antiarrhythmic medications was left to the discretion of the attending physicians, but physicians chose drugs according to local guidelines. For example, digitalis was usually used to slow the ventricular rate during AF in our ICU. Furthermore, the attending physicians were also unaware of the study objectives. More patients received digitalis in the propofol group than in the dexmedetomidine group (see Additional file 1), which is mostly due to a greater number of postoperative AF incidents among patients receiving propofol.

Third, although the elderly patients were more likely to have postoperative AF, the patients in this study were younger than those in most other studies (mean age, 54 vs approximately 65 years) [1, 3, 31]. Moreover, only 16 patients in our study $(18.2 \%)$ were $\geq 65$ years old. Therefore, additional studies are needed to investigate the effects of dexmedetomidine on the prevention of postoperative $\mathrm{AF}$ in elderly patients after cardiac surgery.

Fourth, tests about the secondary end points (e.g., the length of ICU stay) and the incidence of adverse events (e.g., hypotension) were performed without adjusting for multiple testing in this study. Therefore, these results are explorative and confirmatory studies are needed. However, our primary endpoint, the incidence of postoperative AF, was a single primary endpoint and therefore no adjustments are needed [45].

\section{Conclusions}

Our results demonstrated that the use of dexmedetomidine might be efficacious in the prevention of postoperative $\mathrm{AF}$ and could be beneficial in reducing medical resource utilization in patients after cardiac surgery. Larger RCTs are needed to confirm our findings.

\section{Key messages}

- Patients with new onset postoperative AF were significantly older and had a longer ICU stay, more postoperative hospital days and increased hospital fees

- Dexmedetomidine sedation reduced new-onset postoperative $\mathrm{AF}$ and shortened the ICU stay in patients after cardiac surgery compared to propofol sedation

- The administration of dexmedetomidine during the early postoperative period could prevent one case of AF for every five patients undergoing cardiac surgery

\section{Additional file}

Additional file 1: Table S1. Postoperative medication use of the patients in propofol and dexmedetomidine groups. Description of data: medications were used within $96 \mathrm{~h}$ after cardiac surgery (DOCX $13 \mathrm{~kb}$ )

\section{Abbreviations}

AF: Atrial fibrillation; AKIN: Acute Kidney Injury Network; BMI: Body mass index; CK-MB: Creatine kinase-MB; COPD: Chronic obstructive pulmonary disease; CPB: Cardiopulmonary bypass; CTnl: Cardiac troponin I;

ECG: Electrocardiogram; ICU: Intensive care unit; LVEF: Left ventricular ejection fraction; MAP: Mean arterial pressure; NYHA: New York Heart Association; RASS: Richmond agitation-sedation scale; RCT: Randomized controlled trial; VAS: visual analog scale

\section{Acknowledgements}

We would like to thank the patients, nurses and physicians who participated in the study.

\section{Funding}

Not applicable.

\section{Availability of data and materials Not applicable.}

\begin{abstract}
Authors' contributions
$X \mathrm{~L}$ participated in the design of the study, collected the data, performed the statistical analysis and drafted the manuscript. KZ participated in the design of the study, collected the data and helped to draft the manuscript. WW participated in the design of the study, collected the data and helped to revise the manuscript. GHX performed the statistical analysis and revised the manuscript. XMF conceived of the study, and participated in its design and coordination and revised the manuscript. All authors read and approved the final manuscript.
\end{abstract}

Competing interests

The authors declare that they have no competing interests. 


\section{Consent for publication}

Not applicable.

\section{Ethics approval and consent to participate}

The trial was approved by the Ethics Committee of the First Affiliated Hospital of Zhejiang University and registered at chictr.org.cn (ChiCTR-IPR-16008231). Written informed consent was obtained from the patient or next of kin before enrollment.

\section{Received: 6 May 2016 Accepted: 6 September 2016}

\section{Published online: 21 September 2016}

\section{References}

1. Imazio M, Brucato A, Ferrazzi P, Pullara A, Adler Y, Barosi A, et al. Colchicine for prevention of postpericardiotomy syndrome and postoperative atrial fibrillation: the COPPS-2 randomized clinical trial. JAMA. 2014;312:1016-23.

2. Burgess DC, Kilborn MJ, Keech AC. Interventions for prevention of postoperative atrial fibrillation and its complications after cardiac surgery: a meta-analysis. Eur Heart J. 2006;27:2846-57.

3. Halonen J, Halonen P, Jarvinen O, Taskinen P, Auvinen T, Tarkka M, et al. Corticosteroids for the prevention of atrial fibrillation after cardiac surgery: a randomized controlled trial. JAMA. 2007:297:1562-7.

4. Worden JC, Asare K. Postoperative atrial fibrillation: role of inflammatory biomarkers and use of colchicine for its prevention. Pharmacotherapy. 2014;34:1167-73

5. Raiten JM, Ghadimi K, Augoustides JG, Ramakrishna H, Patel PA, Weiss SJ, et al. Atrial fibrillation after cardiac surgery: clinical update on mechanisms and prophylactic strategies. J Cardiothorac Vasc Anesth. 2015;29:806-16.

6. Mathew JP, Fontes ML, Tudor IC, Ramsay J, Duke P, Mazer CD, et al. A multicenter risk index for atrial fibrillation after cardiac surgery. Jama. 2004:291:1720-9.

7. Kerstein J, Soodan A, Qamar M, Majid M, Lichstein E, Hollander G, et al. Giving IV and oral amiodarone perioperatively for the prevention of postoperative atrial fibrillation in patients undergoing coronary artery bypass surgery: the GAP study. Chest. 2004;126:716-24.

8. van Osch D, Dieleman JM, van Dijk D, Jacob KA, Kluin J, Doevendans PA, et al. Dexamethasone for the prevention of postoperative atrial fibrillation. Int J Cardiol. 2015;182:431-7.

9. Price J, Tee R, Lam BK, Hendry P, Green MS, Rubens FD. Current use of prophylactic strategies for postoperative atrial fibrillation: a survey of Canadian cardiac surgeons. Annals of Thoracic Surgery. 2009;88:106-11.

10. Lutz JM, Panchagnula U, Barker JM. Prophylaxis against atrial fibrillation after cardiac surgery: effective, but not routinely used-a survey of cardiothoracic units in the United Kingdom. J Cardiothorac Vasc Anesth. 2011;25:90-4.

11. Melby SJ. Might a beta blocker finally provide some relief from postoperative atrial fibrillation? J Thorac Cardiovasc Surg. 2015;150:965-6.

12. Tran DT, Perry JJ, Dupuis JY, Elmestekawy E, Wells GA. Predicting new-onset postoperative atrial fibrillation in cardiac surgery patients. J Cardiothorac Vasc Anesth. 2015;29:1117-26.

13. Pandharipande PP, Pun BT, Herr DL, Maze M, Girard TD, Miller RR, et al. Effect of sedation with dexmedetomidine vs lorazepam on acute brain dysfunction in mechanically ventilated patients: the MENDS randomized controlled trial. JAMA. 2007;298:2644-53.

14. Stephens RS, Whitman GJ. Postoperative critical care of the adult cardiac surgical patient. Part I: routine postoperative care. Crit Care Med. 2015;43:1477-97.

15. Lin $Y Y$, He B, Chen J, Wang ZN. Can dexmedetomidine be a safe and efficacious sedative agent in post-cardiac surgery patients? A meta-analysis. Crit Care. 2012:16:R169.

16. Ji F, Li Z, Nguyen H, Young N, Shi P, Fleming N, et al. Perioperative dexmedetomidine improves outcomes of cardiac surgery. Circulation. 2013;127:1576-84

17. Tobias JD, Chrysostomou C. Dexmedetomidine: antiarrhythmic effects in the pediatric cardiac patient. Pediatr Cardiol. 2013;34:779-85.

18. Chrysostomou C, Beerman L, Shiderly D, Berry D, Morell VO, Munoz R. Dexmedetomidine: a novel drug for the treatment of atrial and junctional tachyarrhythmias during the perioperative period for congenital cardiac surgery: a preliminary study. Anesth Analg. 2008;107:1514-22.

19. Chrysostomou C, Sanchez-de-Toledo J, Wearden P, Jooste EH, Lichtenstein SE, Callahan PM, et al. Perioperative use of dexmedetomidine is associated with decreased incidence of ventricular and supraventricular tachyarrhythmias after congenital cardiac operations. Annals of Thoracic Surgery. 2011;92:964-72

20. Chrysostomou C, Morell VO, Wearden P, Sanchez-de-Toledo J, Jooste EH, Beerman L. Dexmedetomidine: therapeutic use for the termination of reentrant supraventricular tachycardia. Congenit Heart Dis. 2013;8:48-56.

21. Turan A, Bashour CA, You J, Kirkova Y, Kurz A, Sessler DI, et al. Dexmedetomidine sedation after cardiac surgery decreases atrial arrhythmias. J Clin Anesth. 2014;26:634-42.

22. Narisawa A, Nakane M, Kano T, Momose N, Onodera Y, Akimoto R, et al. Dexmedetomidine sedation during the nighttime reduced the incidence of postoperative atrial fibrillation in cardiovascular surgery patients after tracheal extubation. J Intensive Care. 2015;3:26.

23. Jakob SM, Ruokonen E, Grounds RM, Sarapohja T, Garratt C, Pocock SJ, et al. Dexmedetomidine vs midazolam or propofol for sedation during prolonged mechanical ventilation: two randomized controlled trials. JAMA. 2012;307:1151-60

24. Barr J, Fraser GL, Puntillo K, Ely EW, Gelinas C, Dasta JF, et al. Clinical practice guidelines for the management of pain, agitation, and delirium in adult patients in the intensive care unit. Crit Care Med. 2013;41:263-306.

25. Block BM, Liu SS, Rowlingson AJ, Cowan AR, Cowan Jr JA, Wu CL. Efficacy of postoperative epidural analgesia: a meta-analysis. JAMA. 2003:290:2455-63.

26. Cheung CC, Martyn A, Campbell N, Frost S, Gilbert K, Michota F, et al. Predictors of intraoperative hypotension and bradycardia. Am J Med. 2015;128:532-8.

27. Mehta RL, Kellum JA, Shah SV, Molitoris BA, Ronco C, Warnock DG, et al. Acute Kidney Injury Network: report of an initiative to improve outcomes in acute kidney injury. Crit Care. 2007;11:R31.

28. Mozaffarian D, Marchioli R, Macchia A, Silletta MG, Ferrazzi P, Gardner TJ, et al. Fish oil and postoperative atrial fibrillation: the Omega-3 Fatty Acids for Prevention of Post-operative Atrial Fibrillation (OPERA) randomized trial. JAMA. 2012;308:2001-11.

29. Wunsch H, Kahn JM, Kramer AA, Wagener G, Li GH, Sladen RN, et al. Dexmedetomidine in the care of critically ill patients from 2001 to 2007 an observational cohort study. Anesthesiology. 2010;113:386-94.

30. Geng J, Qian J, Cheng H, Ji F, Liu H. The influence of perioperative dexmedetomidine on patients undergoing cardiac surgery: a meta-analysis. PLoS One. 2016;11, e0152829.

31. Herr DL, Sum-Ping ST, England M. ICU sedation after coronary artery bypass graft surgery: dexmedetomidine-based versus propofol-based sedation regimens. J Cardiothorac Vasc Anesth. 2003;17:576-84.

32. Shehabi $Y$, Grant P, Wolfenden H, Hammond N, Bass F, Campbell M, et al. Prevalence of delirium with dexmedetomidine compared with morphine based therapy after cardiac surgery: a randomized controlled trial (DEXmedetomidine COmpared to Morphine-DEXCOM Study). In: Anesthesiology vol. 2009;111:1075-84.

33. Park JB, Bang SH, Chee HK, Kim JS, Lee SA, Shin JK. Efficacy and safety of dexmedetomidine for postoperative delirium in adult cardiac surgery on cardiopulmonary bypass. Korean J Thorac Cardiovasc Surg. 2014;47:249-54.

34. Karaman Y, Abud B, Tekgul ZT, Cakmak M, Yildiz M, Gonullu M. Effects of dexmedetomidine and propofol on sedation in patients after coronary artery bypass graft surgery in a fast-track recovery room setting. J Anesth. 2015;29:522-8.

35. Balkanay OO, Goksedef D, Omeroglu SN, Ipek G. The dose-related effects of Dexmedetomidine on renal functions and serum neutrophil gelatinaseassociated lipocalin values after coronary artery bypass grafting: a randomized, triple-blind, placebo-controlled study. Interact Cardiovasc Thorac Surg. 2015;20:209-14.

36. Ren J, Zhang H, Huang L, Liu Y, Liu F, Dong Z. Protective effect of dexmedetomidine in coronary artery bypass grafting surgery. Exp Ther Med. 2013;6:497-502.

37. Hu YF, Chen YJ, Lin YJ, Chen SA. Inflammation and the pathogenesis of atrial fibrillation. Nat Rev Cardiol. 2015;12:230-43.

38. Taniguchi $T$, Kidani $Y$, Kanakura $H$, Takemoto $Y$, Yamamoto K. Effects of dexmedetomidine on mortality rate and inflammatory responses to endotoxin-induced shock in rats. Crit Care Med. 2004;32:1322-6.

39. Xiang $\mathrm{H}, \mathrm{Hu} B, \mathrm{Li} Z \mathrm{Z}, \mathrm{Li}$ J. Dexmedetomidine controls systemic cytokine levels through the cholinergic anti-inflammatory pathway. Inflammation. 2014;37:1763-70

40. Ueki M, Kawasaki T, Habe K, Hamada K, Kawasaki C, Sata T. The effects of dexmedetomidine on inflammatory mediators after cardiopulmonary bypass. Anaesthesia. 2014;69:693-700. 
41. Tasdogan M, Memis D, Sut N, Yuksel M. Results of a pilot study on the effects of propofol and dexmedetomidine on inflammatory responses and intraabdominal pressure in severe sepsis. J Clin Anesth. 2009;21:394-400.

42. Shingu Y, Kubota S, Wakasa S, Ooka T, Tachibana T, Matsui Y. Postoperative atrial fibrillation: mechanism, prevention, and future perspective. Surg Today. 2012;42:819-24.

43. Mukhtar AM, Obayah EM, Hassona AM. The use of dexmedetomidine in pediatric cardiac surgery. Anesth Analg. 2006;103:52-6.

44. Hayashi Y, Sumikawa K, Maze M, Yamatodani A, Kamibayashi T, Kuro M, et al. Dexmedetomidine prevents epinephrine-induced arrhythmias through stimulation of central alpha 2 adrenoceptors in halothane-anesthetized dogs. Anesthesiology. 1991;75:113-7.

45. Bender R, Lange S. Adjusting for multiple testing - when and how? J Clin Epidemiol. 2001;54:343-9.

Submit your next manuscript to BioMed Central and we will help you at every step:

- We accept pre-submission inquiries

- Our selector tool helps you to find the most relevant journal

- We provide round the clock customer support

- Convenient online submission

- Thorough peer review

- Inclusion in PubMed and all major indexing services

- Maximum visibility for your research

Submit your manuscript at www.biomedcentral.com/submit
Biomed Central 